\title{
OPTICAL FIBER BRAGG GRATING TEMPERATURE SENSOR
}

\author{
Marwan L. Yousf ${ }^{1}$, Ihssan A. Kadham ${ }^{2}$, Tahreer S. Mansour ${ }^{3}$, Khalil I. Hajim ${ }^{4}$ \\ ${ }^{1,2}$ M.Sc. Students, ${ }^{3}$ Lecturer, ${ }^{4}$ Prof., Institute of Laser for Postgraduate Studies, University of Baghdad \\ E-mail: aa_marwan1985@yahoo.com
}

(Received: 17/11/2013; Accepted: 12/12/2013)

\begin{abstract}
In this work, uniform Fiber Bragg Grating (FBG) temperature sensor system were implemented and investigated due to measurement of the Bragg wavelength shift. An (FBG) is an optical fiber in which the refractive index in the core is perturbed by Germanium, forming a periodic index modulation profile. When light is guided through a fiber granting, it is scattered at each diffraction plane, except at those wavelengths which satisfy the Bragg resonance condition
\end{abstract}

An important application of FBG technology is sensing. The reflected wavelength from the FBG depends on physical properties such as temperature. By integration the FBG with broadband light, the shift in peak reflectivity wavelength can be used as a measure for the temperature.

It has been shown from the results that the FBG is very sensitive to variations in temperature degrees and the sensitivity was $\left(1 \mathrm{pm} / 0.1^{\circ} \mathrm{C}\right)$, also observed from the results, the relation between the shifted Bragg wavelength and temperature degrees was linear.

Keyword: Fiber Bragg Grating, Temperature Electrical Controller, Fiber Bragg Grating Analyzer

\section{1- INTRODUCTION}

The fiber Bragg gratings (FBGs) are simple sensing elements ${ }^{(1)}$. The fiber Bragg grating $(\mathrm{FBG})$ is a piece of optical fiber with periodic variation of the index of refraction along the fiber axis ${ }^{(2)}$. The fiber Bragg grating (FBG) is typically formed within the core of a single mode optical fiber. The grating consists of a series of regions of increased refractive index $(n)$, spaced at a regular period $(\Lambda)^{(3)}$. The formation of a FBG is generally based on the photo-sensitivity of silica fiber doped with germanium. When illuminated by UV radiation, the fiber exhibits a permanent change in the refractive index of the core ${ }^{(1)}$. One of the most important properties of the FBG is wavelength selective reflection ${ }^{(4)}$. There are several 
distinct types of Fiber Bragg Grating structures such as the common Bragg reflector or uniform FBG, the blazed Bragg grating, and the chirped Bragg grating. These Fiber Bragg gratings are distinguished either by their grating pitch, spacing between grating planes or tilt angle between grating planes and fiber axis. The most common Fiber Bragg Grating is the Bragg reflector or uniform fiber Bragg grating ${ }^{(5)}$. For a uniform FBG, the period $(\Lambda)$ remains constant throughout the length and the reflection is the strongest at the Bragg wavelength $\left(\lambda_{B}\right)$. The Bragg resonant wavelength is a function of the period $(\Lambda)$ and the mode effective index ( $\left.\mathrm{n}_{\mathrm{eff}}\right)$ which is given by:

$$
\lambda_{\mathrm{B}}=2 \text { neff } \Lambda
$$

Where $\mathrm{n}_{\text {eff }}$ is the effective index ${ }^{(1)}, \wedge$ is the grating period ${ }^{(1)}$.

Bragg grating wavelength depends on the effective index of refraction of the core and the periodicity of the grating. It can be used to monitor the changes in strain and temperature ${ }^{(6)}$.

The temperature sensing of Bragg grating occurs principally through the temperature effect on the index of refraction and to a less extent through the expansion coefficient. The maximum operating temperature may be around $\left(500{ }^{\circ} \mathrm{C}\right)$; however this may depend on the fabrication condition of the Bragg grating ${ }^{(7)}$. The principle of the dielectric Bragg grating temperature sensor is based on the measurement of the reflected Bragg wavelength. The fiber Bragg grating FBG temperature sensor reflects one particular wavelength and transmits all others and the reflected wavelength can vary with the temperature of the sensor; thus fiber Bragg grating FBG temperature sensors have been widely used in applications in monitoring temperature ${ }^{(4)}$.

$$
\Delta T=\frac{1}{k * \alpha_{\text {glass }}+\alpha_{\delta}} * \frac{\Delta \lambda}{\lambda_{o}}
$$

Where:-

$\Delta \lambda=$ Wavelength shift, $\lambda_{0}=$ Base wavelength at the start of the test.

$$
\mathrm{k}=1-\mathrm{p}
$$

$\mathrm{p}=$ photo-elastic coefficient, $\mathrm{p}=0.22, \mathrm{k}=$ gage factor, $\mathrm{k}=0.78, \Delta \mathrm{T}=$ temperature change in Kelvin, $\alpha \delta=$ change of the refraction index, $\boldsymbol{\alpha}_{\delta}=5 \ldots 8^{*} 10^{-6} /$ Kelvin, $\alpha_{\text {glass }}=$ the thermal expansion coefficient of the fiber, where $\alpha$ of glass $=0.55^{*} 10^{-6} /$ Kelvin.

The expansion coefficient ( $\left.\alpha_{\text {glass}}\right)$ of the fiber is very low; almost zero. The biggest impact results from the temperature dependent change of the refraction index $(\alpha \delta){ }^{(7)}$.

\section{2- EXPERIMENTAL SETUP}

At the beginning, the system was designed as shown in Figure (1). So we can get results of the shifting in wavelengths because temperature impact on the fiber Bragg grating sensor, the source will be connected with all its parts (Temperature Controller TED200C, 
Laser Diode Controller and the mount). The IC Chipset is the main part from the source and connected to single mode fiber terminated by an FC connector.

The first port of the circulator is connected to the FC connector where it leads to the source, while the second port of the circulator is connected to the FC connector. It leads to the fiber Bragg grating sensor. The third port of the circulator is connected to the fiber Bragg grating analyzer (FBGA).

Special design of temperature measurement was designed, where the fiber Bragg grating sensor wavelength will be affected with change of temperatures, and this effect will appear on the amount of shifting for the optical signal.

The reflected signal from FBG is analyzed by FBGA, the program sense (20\20) which was installed on PC read out the reflected data.

\section{3- RESULTS AND DISCUSSION}

As shown in Figures (2-4), constant values of current is taken. This value is (100mA). The value of temperatures of the temperature electrical controller (TEC) are fixed on at (0 $\left.{ }^{\circ} \mathrm{C}\right)$. The power of the signal remains constant and at $(0.11 \mathrm{~mW})$. This cause leads that case, the temperatures of the temperature electrical controller (TEC) remain constant. So that, the power of the signal will remain constant.

The external temperatures increase steps of $\left(0.1^{\circ} \mathrm{C}\right)$ which affect the central wavelength of FBG sensor which is directly proportional with temperatures.

The goal from this work is to know the upper sensitive where the fiber Bragg grating analyzer (FBGA) has happened on it. The value of temperatures of the temperature electrical controller (TEC) are fixed on at $\left(0^{\circ} \mathrm{C}\right)$ so the current of laser diode current (LDC) was fixed on value $(100 \mathrm{~mA})$. The cause is not know the shifting of wavelength and so amount of Bragg wavelength $(\lambda \mathrm{B})$. Although Bragg wavelength $(\lambda \mathrm{B})$ increases when the external temperatures increase. All these cases are shown in figures (2, 3 and 4).

\section{4- CONCLUSION}

The used fiber Bragg grating (FBG) in this work is very sensitive to the variation of

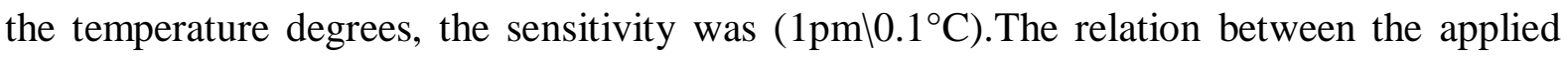
temperature and shifting Brag wavelength is linear. The sensitivity of the Bragg wavelength to temperature arises from the change in the refractive index of the optical fiber.

\section{5- REFERENCES}

1. Cheung Chi Shing, "An investigation of chirped fiber Bragg gratings Fabry-Perot interferometer for sensing applications", $\mathrm{PhD}$ thesis, Optical sensor group, Center of photonics and optical engineering school of engineering, (2004). 
2. Najeeb Mohammad, "Analysis and development of a tunable fiber Bragg grating filter based on axial Tension\Compression" M.sc thesis, Department of Mechanical Engineering, University of Saskatchewan Saskatoon, Canada, (2005).

3. C. R. S. Dennison, "Development and application of in-fiber Bragg grating based biomedical pressure sensors", M.sc thesis, University of Victoria, (2008).

4. B. Zhang and M. Kahrizi, "Characteristics of fiber Bragg grating temperature sensor at elevated temperatures”, Department of Electrical and Computer Engineering, Concordia University, (2005).

5. N. S. Aulakh, "Investigation on fiber Bragg gratings for fiber optic communication systems" PhD thesis, THAPAR UNIVERSITY, (2010).

6. Regina Gumenyuk, "Fabrication technology and applications of fiber Bragg gratins" M.Sc. thesis, Lappeenranta University of Technology (2008).

7. Manfred Kreuzer, "Strain measurement with fiber Bragg grating sensor", HBM, Darmstadt, Germany.

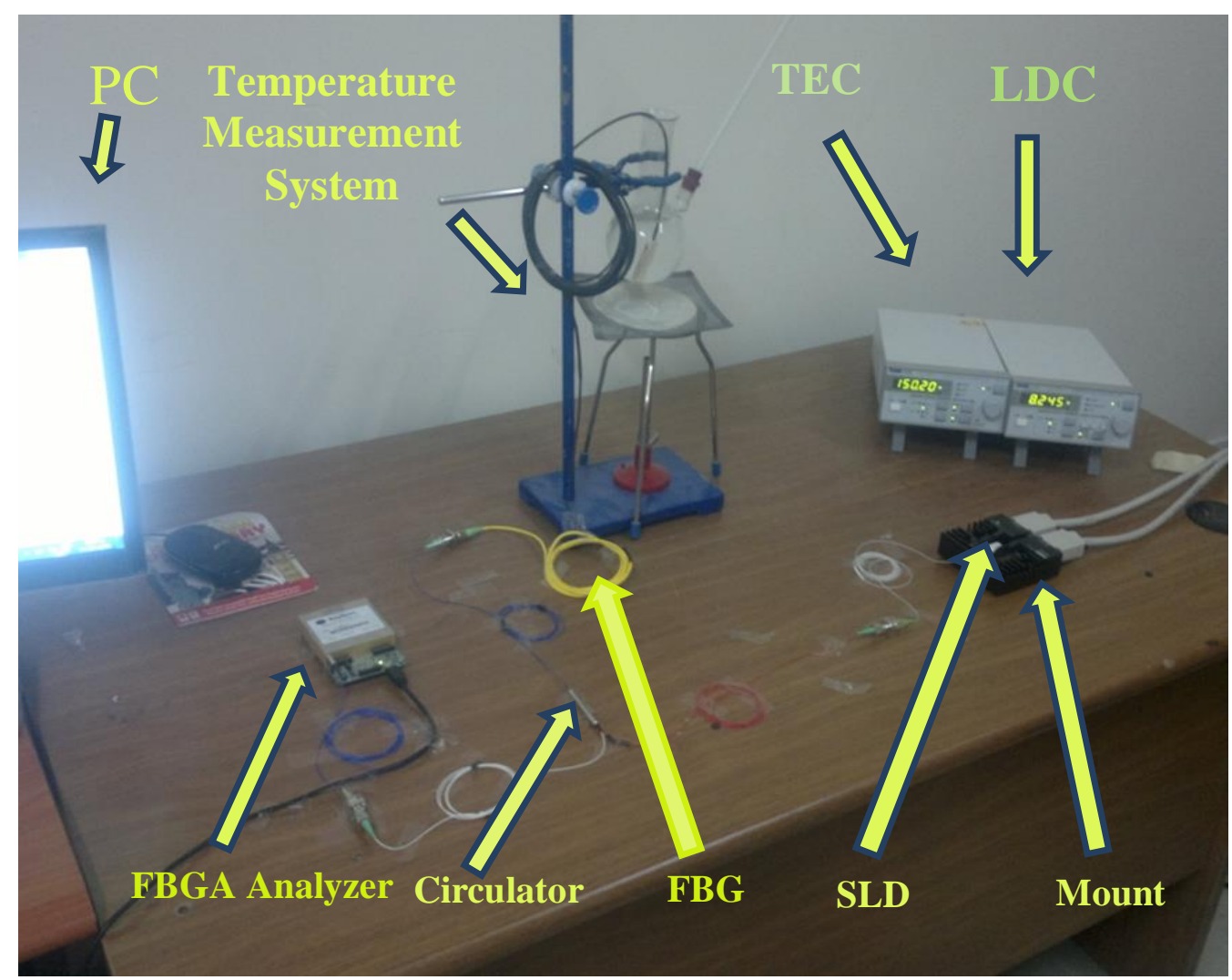

Fig (1): the system layout of fiber Bragg grating temperature sensor. 


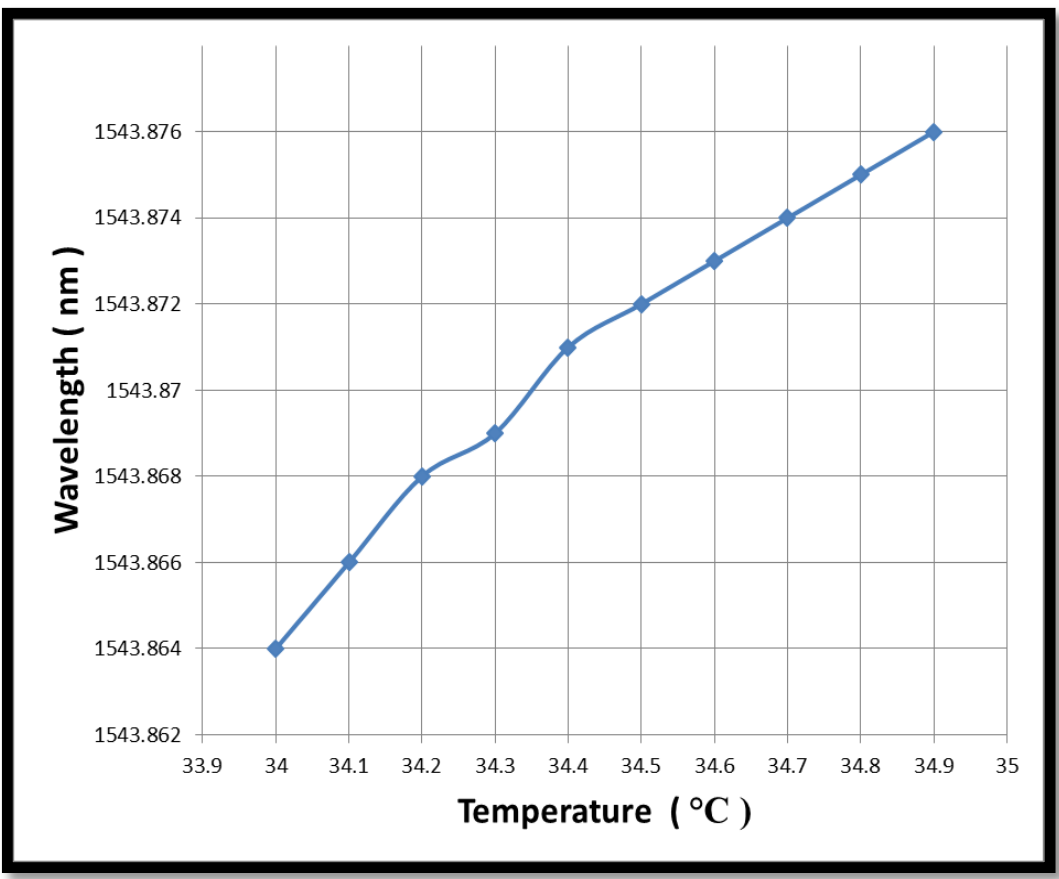

Fig (2): the relationship between Wavelength and Temperature.

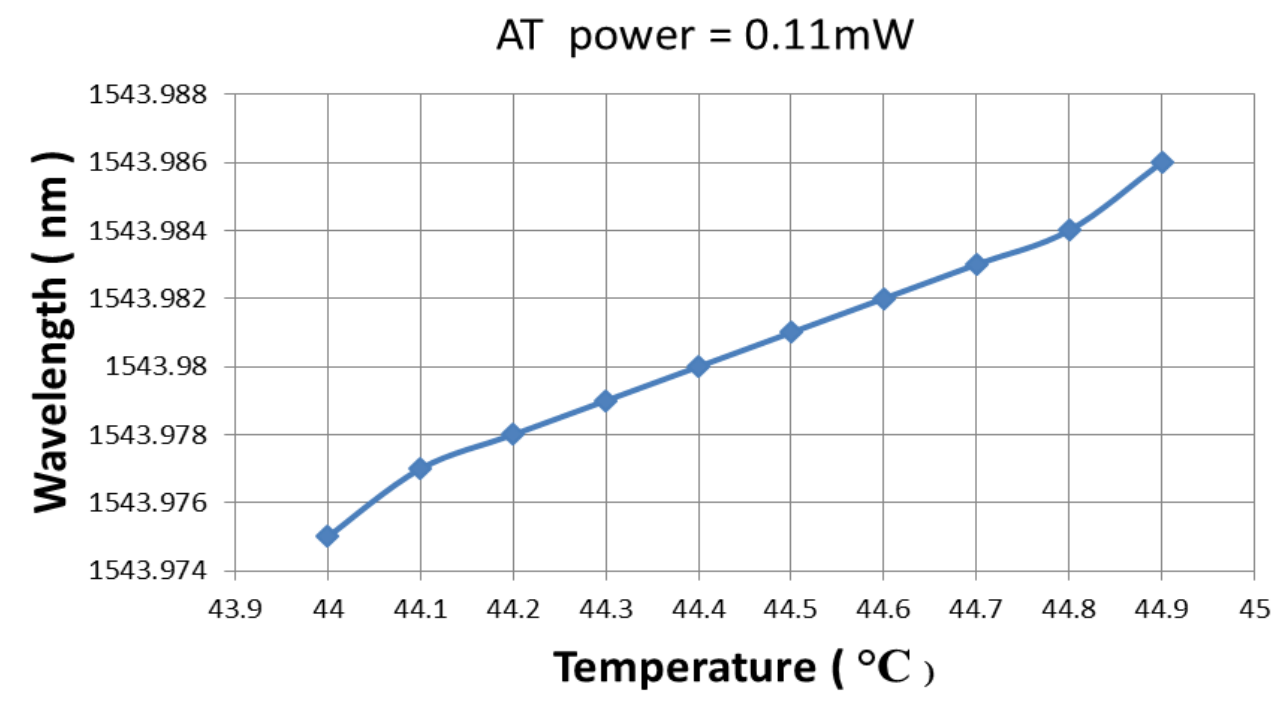

Fig (3): the relationship between Wavelength and Temperature. 


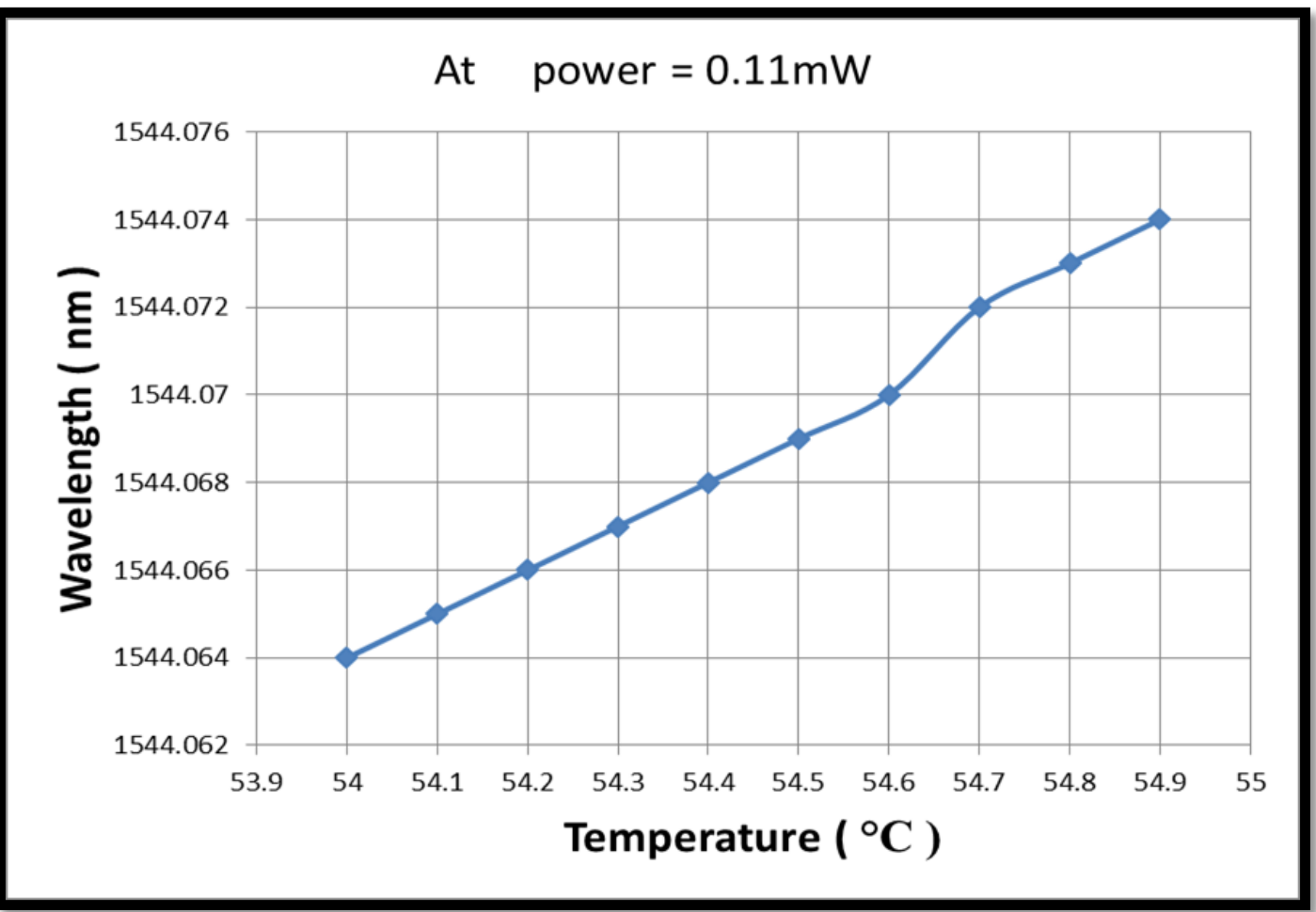

Fig (4): the relationship between Wavelength and Temperature. 


\section{محزز براك للألباف البصرية المتحس للحرارة}

\section{مروان لطفي يوسف 1، احسان علي كاظم 2، تحرير صفاء منصور 3، خليل (براهيم حاجم 4}

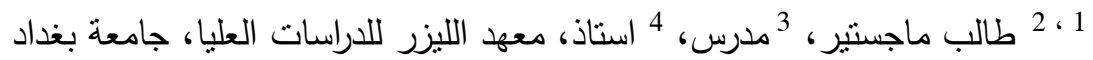

في هذا البحث تم تحقيق منظومة تحسس للحرارة باستخدام محززالليف البصري نوع براغ أستناداً على قياس إزاحة الطول الموجي لمحزز براغ. محزز الليف البصري نوع براغ المستخدم في العمل الحالي يصنع بواسطة تثويب الجرمانيوم في قلب الليف البصري المشكل كمعامل أنكسار دوري.

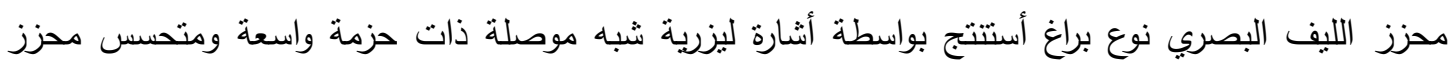

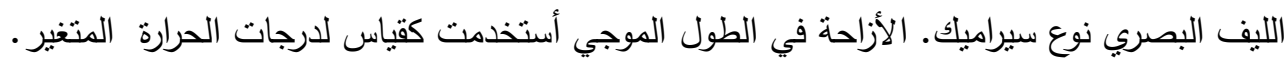

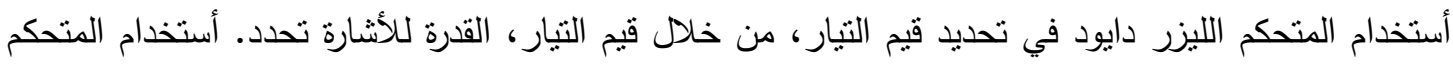

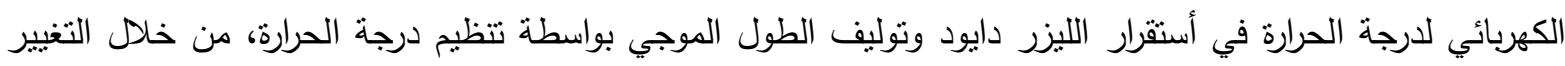

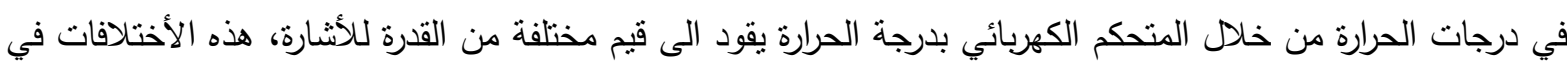
قيم القدرة تقود الى نغير في قيمة الطول الموجي نوع براك الك.

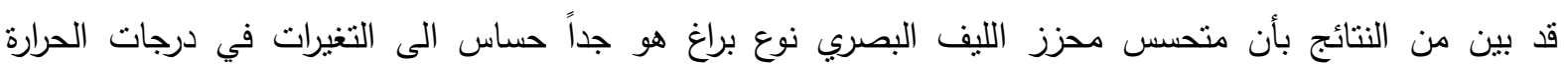

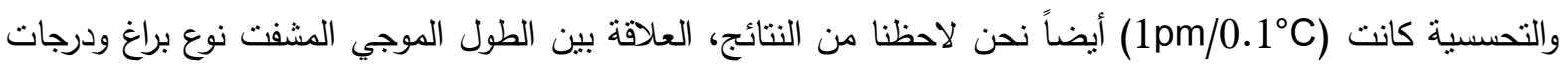
الحرارة كانت خطية. الكلمة المفتاحية: محزز الألياف نوع براغ، مسيطر كهريائي للحرارة، محلل محزز الألياف نوع براغ. 